\title{
Material Daur Ulang dari Bahan Pisang Sebagai Pelapis Akustik Pada Dinding Interior
}

\author{
Anastasia Cinthya Gani ${ }^{1}$, Augustina Ika Widyani ${ }^{2}$ \\ Fakultas Seni Rupa dan Desain, Universitas Tarumagara ${ }^{1,2}$ \\ anastasiag@fsrd.untar.ac.id
}

\begin{abstract}
Abstrak - Wacana desain yang berkelanjutan (sustainable design) memberikan peluang untuk menggali lebih dalam terhadap kemungkinan-kemungkinan aplikasi material yang ramah lingkungan. Penggunaan bahan dasar dari pohon pisang mudah ditemukan di Indonesia, secara mempunyai iklim tropis. Terutama di Jakarta, dimana mudah ditemukan tanaman pisang dan dapat diambil dari pasar - pasar terdekat. Bagian pohon pisang yang digunakan yaitu pelepah pisang dan bonggol pisang. Kedua bagian tersebut diambil karena sudah menjadi bahan tidak terpakai kembali. Bahan tersebut akan dibuat sebagai bahan pelapis akustik akustik pada interior. Keberhasilan ruang interior dinilai dari kemampuannya dalam menciptakan lingkungan yang dapat mengakomodasi kegiatan dalam ruang tersebut dan memberikan kenyamanan secara inderawi. Kenyamanan inderawi termasuk tuntutan ergonomic, salah satunya adalah kenyamanan akustik, yaitu yang berhubungan dengan suara dengan batasan kemampuan indera penderangan manusiaOleh karena itu perlu suatu perlakuan khusus terhadap ruang interior untuk mengatasi permasalahan tersebut. Salah satu cara untuk mencapai kenyamanan akustik adalah dengan mengurangi tingkat kebisingan dalam ruang melalui aplikasi pelapis akustik. Penelitian kali ini, parameter penilaian yang digunakan yaitu terlebih dahulu mengukur koefisien absorpsi untuk mengetahui seberapa besar bahan tersebut dapat menyerap atau memantulkan golombang suara. Dengan hipotesa yang menyatakan bahwa bahan dasar alami dapat menyerap gelombang suara, maka hasil dari pegujian material tersebut membuktikan bahwa bahan tersebut efektif dalam menyerap gelombang suara.
\end{abstract}

Kata kunci: Limbah Pohon Pisang, Pelapis Akustik, Desain Interior

\section{PENDAHULUAN}

Penggunaan bahan daur ulang terutama dari bahan yang sudah tidak terpakai merupakan salah satu upaya dalam pelestarian lingkungan (Adiwijaya, 2011; Jayanti, 2013). Untuk di daerah Jakarta, bahan bonggol pisang merupakan salah satu bahan yang mudah didapat (SE, 2002). Bahan tersebut dapat didaur ulang menjadi material yang dapat dipakai kembali seperti kertas daur ulang. Dalam penelitian ini, penggunaan material baru ditujukan untuk pengaplikasian finishing akustik pada dinding interior.
Pelepah maupun bonggol pisang mempunyai serat yang cukup padat, maka pemilihan material tersebut diharapkan dapat memenuhi kriteria sebagai bahan akustik (Indrawati \& Tirono, 2012; Nurjannah, 2016; Permanasari, Larasati, \& Widiawati, 2014). Langkah awal yang diperhatikan yaitu mengetahui karakteristik dari material tersebut.

\section{Batasan Penelitian}

Batasan penelitian ini adalah hanya untuk mengetahui karakteristik material baru. Perhitungan koefisien perlu diketahui untuk 
memastikan apakah material tersebut dapat dipakai sebagai bidang serap atau bidang pantul, sehingga tepat pengaplikasiannya.

Bahan material tersebut, terbuat dari bonggol pisang, bahan ini dipilih kareana mudah didapat di wilayah sekitar Jakarta. Bonggol pisang pun tidak tergantung dari musim, sehingga setiap saat bisa didapatkan (Suharyani \& Mutiari, 2015).

Adapun beberapa manfaat dari penelitian ini yaitu :

1. Mendayagunakan bonggol pisang menjadi bahan yang dapat digunakan kembali menjadi material akustik interior.

2. Menambah jenis material akustik yang dapat diterapkan pada desain interior.

3. Menjadi alternatif dalam menambah penghasilan masyarakat yang seharihari bersinggungan dengan bonggol pisang.

Prinsip dasar akustik yaitu sumber bunyi suara dapat diterima oleh pendengarnya ( $A$. Sutanto, Priatman, \& Mediastika, 2014; H. Sutanto, 2015). Hal yang perlu diperhatikan dalam penelitian ini yaitu bahan absorbsi secara umum berfungsi untuk menyerap energi suara dengan tujuan menyeimbangkan reverberation time, menyerap gangguan yang tidak diinginkan, menghilangkan rentang fekuensi tertentu dan fungsi lainnya. Selain menambah kualitas akustik di suatu ruangan, aspek kenyamanan dan kesesuaian dengan komponen lain, misalnya pencahayaan, arsitektur, dan lainnya, harus diperhatikan juga (Bazley, Vink, \& de Jong, 2014).

Setiap bahan absorbsi mempunyai koefisien absorbsi yang berbeda (Berardi \& lannace, 2015; Khuriati \& Komaruddin, 2006). Koefisien absorbsi suara suatu bahan didefinisikan sebagai perbandingan antara energi akustik yang diserap dengan energi akustik yang datang menimpa bahan tersebut (Shahani, Soltani, \& Zarrebini, 2014). Koefisien absorbsi suara suatu bahan dapat dihitung dengan menggunakan formula.

$\alpha=$ Koefisien absorbsi suara $\mathrm{la}=$ Intensitas suara yang diserap $\left(\mathrm{W} / \mathrm{m}^{2}\right)$ $\mathrm{li}=$ Intensitas suara yang datang $\left(\mathrm{W} / \mathrm{m}^{2}\right)$

Intensitas mempunyai energi yang dibawa. Semakin banyak intensitas yang dibawa, semakin banyak energi yang dibawa. Koefisien absorbsi sudah pasti kurang dari 1. Oleh karena itu, dipastikan ada energi yang hilang. 
Pada umumnya untuk memenuhi kebutuhan absorbsi ada tiga bahan yang digunakan, di antara 3 bahan itu adalah:

\section{Porous}

Porous ini berfungsi sebagai penyerap energi suara menjadi energi lain. Jadi ada energi suara yang diubah menjadi energi panas, dan hal ini mengakibatkan suara yang dipantulkan menjadi berkurang (Dragna, Pineau, \& BlancBenon, 2016).

Di antara karakteristik bahan untuk absorbsi adalah:

- Pada frekuensi rendah $\alpha$ Kecil

- Makin tinggi frekuensi a Makin besar, atau dengan Makin tebal bahan, $\alpha$ Makin besar

- Pengecatan akan mengurangi nilai $\alpha$

- Rongga udara akan memperbesar nilai $\alpha$

Material Porous yang biasa dikomersilkan bisa dibagi menjadi 3:

a. Unit akustik yang siap pasang (Prefabricated acoustical Unit)

Di pasaran sudah ada berbagai macam material akustik yang siap pasang atau siap rakit, material bisa berupa panel yang berlubang, atau texture atau yang lainnya. Bisa dipasang dengan beberapa cara, salah satunya dengan menyemen dengan dinding, menempelkan dengan baut ke dinding kayu atau cara lainnya. Kelebihan dengan unit akustik yang siap pasang di antaranya adalah:
1. Dijamin kualitas absorbsi oleh industri pembuatnya

2. Pemasangan dan perawatan relatif lebih mudah dan lebih murah

3. Bisa dihias tanpa memberi efek yang besar terhadap kemampuan absorbsinya.

4. Apabila digunakan di langit-langit bisa diintegrasikan dengan keperluan dari pencahayaan, pemanasan atau pendinginan,.

5. Jika dipasang secara tepat, kemampuan absorbsi bisa meningkat sehingga menghasilkan keuntungan

b. Plaster akustik dan material akustik yang disemprotkan

Penggunaan material akustik jenis ini ditujukan untuk mengurangi noise. Selain itu, juga bisa dikarenakan bentuk bangunan yang berbentuk kurva atau bentuknya yang tidak biasa sehingga tidak bisa dipasang material absorbsi dengan cara yang biasa.

Efisiensinya bagus pada frekuensi tinggi, tetapi hal ini terkadang dipengaruhi oleh berbagai faktor pada waktu pemasangan, misal ketebalan dan lain-lain. Kesulitan menggunakan material ini adalah kerentanan terhadap kerusakan ketika dilakukan dekorasi ulang terhadap ruanngannya. 
c. Selimut akustik (Isolation Blanket)

Selimut akustik biasanya dibentuk dari wool, fiberglass, dan lain-lain. Biasanya dipakai untuk memvariasikan ketebalan material akustik di antara (25 sampai $125 \mathrm{~mm}$ ). Kemampuan absorbsi meningkat seiring dengan ketebalan yang dimiliki oleh selimut.

\section{d. Karpet dan serat}

Sebagai tambahan saja bahwa pemasangan karpet dan serat juga ikut berperan untuk menyerap energi suara. Di Indonesia, ada juga yang sedang dikembangkan untuk bahan alternatif seperti misalnya serabut kelapa.

\section{Panel Absorbsi}

Cara kerja panel absorbsi menyerap energi getaran dengan cara meneruskan energi suara yang bisa menembus medium lalu terusan energi suara itu diubah ke energi panas. Pengubahan ke energi panas melalui getaran lendutan (flexural vibration).

Panel absorbsi sering kali merupakan suatu absorber yang efisien untuk frekuensi bawah (Cai, Guo, Hu, \& Yang, 2014). Dengan pemilihan bahan yang tepat, panel absorbsi bisa menyeragamkan reverberation time di seluruh frekuensi. Salah satu fungsi penyeraban suara pada fekuensi rendah bisa dilakukan dengan cara memasang panel absorb dengan memberi ruang kosong antara panel dengan dinding.

Salah satu kelebihan dari panel absorbsi adalah tahan dari abrasi dan lebih tahan lama dalam pemakaian (Berardi \& lannace, 2015). Karena kelebihan inilah, panel absorbsi sering dipakai di bagian bawah dinding ruangan.

\section{Rongga (cavity atau Helmhotz) Resonator} Bahan yang ketiga adalah resonator. Resonator berupa sesuatu yang dilampirkan ke dinding aslinya yang di dalamnya terdiri dari "pengurung udara" yang punya keluaran yang sempit (sering disebut sebagai leher) yang merupakan tempat membuat gelombang suara, merambatnya gelombang suara.

\section{Space Absorber atau functional absorber}

Selain ketiga bahan di atas, ada juga absorber lain yang digunakan untuk menyelesaikan permasalahan akustik yang membutuhkan penyelesaian dengan absorber, baik yang bersifat sementara maupun permanen. Salah satunya adalah space absorber, space absorber dipakai ketika suatu bangunan atau daerah membutuhkan perlakuan penyelesaian masalah akustik, tetapi bangunan atau daerahnya tidak memungkinkan untuk diperlakukan perlakuan 
itu. Space absorber atau functional absorber ini mudah dipasang dan dilepas tanpa merusak atau mengubah suatu bentuk di ruangan atau daerah tersebut. Space absorber dipasang dengan cara menggantungkan di langit-langit.

\section{Variable Absorber}

Terkadang suatu ruangan membutuhkan tidak hanya satu macam waktu dengung (reverberation time), akan tetapi juga beberapa waktu dengung lain yang mungkin dibutuhkan untuk keperluan yang berbeda. Hal ini tidak bisa dipenuhi oleh pemasangan material secara konvensional.

\section{METODE}

Dalam penelitian ini menggunakan pendekatan penilaian secara kuantitatif dan riset menggunakan simulasi dan permodelan (simulation and modeling research). Metode ini digunakan untuk mengetahui secara terperinci (dalam bentuk angka). Analisa menggunakan korelasi yaitu membandingkan dua variabel atau lebih (Wang, Arora, Livescu, \& Bilmes, 2015). Dari hasil tersebut dapat kita ketahui hubungan antara perhitungan yang sudah dilakukan. Penelitian korelasi menurut Linda Groat \& David Wang dapat dilakukan untuk menghubungkan dua variabel atau lebih (Groat \& Wang, 2013). Dari hasil korelasi tersebut dapat menghasilkan prediksi yang akan membantu dalam merancang suatu konsep. Material daur ulang akan diukur koef absorpsi. Adapun pengukuran koef absorpsi suara memakai impedance tube (Dupont, Verdière, Leclaire, \& Panneton, 2015; Pierre, Guillermic, Elias, Drenckhan, \& Leroy, 2013). Berikut adalah gambar alat impedance tube yang akan digunakan dalam penelitian ini.

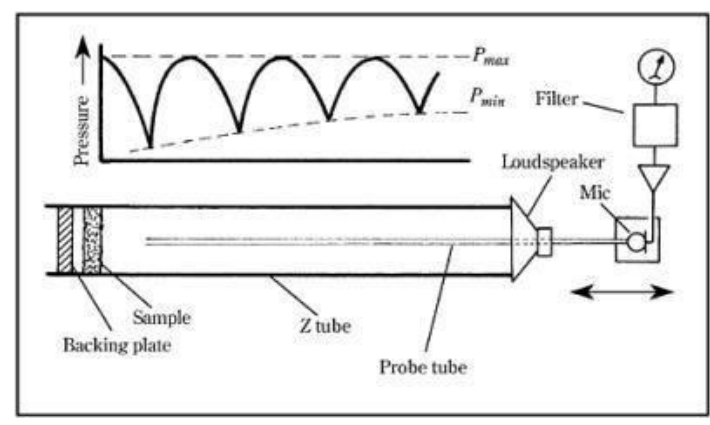

Gambar 1 : Cara kerja Impendance Tube

Adapun alur peneltian yang akan dilakukan, alur tersebut dibuat tabel agar mudah untuk dipahami. Berikut diagram alur penelitian. 


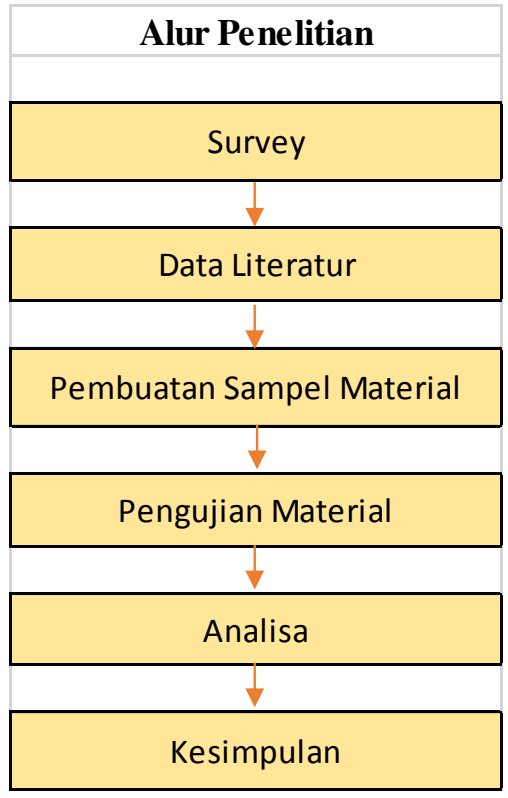

Tabel 1 : Alur penelitian

\section{HASIL DAN PEMBAHASAN}

Penelitian dimulai dengan mengambil sampel yang sudah dibuat, pengambilan sampel menggunakan 2 jenis material yang berasal dari pohon yang sama tetapi bagian yang berbeda (Dewi, 2015). Bagian yang diambil yaitu berasal dari pelepah pisang dan tandan pisang. Untuk proses pembuatan antara tandan pisang dengan pelepah pisang tidaklah jauh berbeda. Kendala yang dihadapi dalam pembuatan banana board ini yaitu getah yang cukup banyak serta faktor cuaca (Tholkappiyan, Saravanan, Jagasthitha, Angeswari, \& Surya, 2016). Getah yang banyak dapat dihilangan menggunakan kaporit, sehingga proses pengeringan bisa cepat dilaukan. Getah yang terkandung dalam pelepah dan tandan pisang akan menghasilkan permukaan banana board cukup mengkilat permukaannya (Jayamania, Hamdanb, Ezhumalaia, \& Bakria, 2016).

Setelah banana board cukup kering, maka proses selanjutnya mencetak banana board tersebut menjadi bentuk lingkaran dengan diameter $10 \mathrm{~cm}$. Ukuran tersebut disesuaikan dengan ukuran sampel yang akan diuji pada impendance tube. Untuk ketebalan, menggunakan ukuran $2,5 \mathrm{~mm}$ dimana ukuran tersebut merupakan ukuran minimal yang dapat dibuat pada banana board. Ketebalan tidak dapat terlalu tipis dikarenakan serat pelepah dan tandan pisang yang cukup kasar. Adapun serat tersebut bisa halus tetapi tidak bisa benar - benar halus seperti bubur. Pemilihan tingkat kekasaran serat juga akan mempengaruhi dari nilai absorb material tersebut serta estetika yang akan ditimbulkan.

Berikut hasil pengujian dari material pelepah pisang dan tandan pisang menggunakan alat impendance tube. Hasil akhir yang dihasilkan berupa grafik yang menunjukkan tingkat absorb berdasarkan frekuensi yang dujikan pada material tersebut.

- Hasil pegujian dari bahan dasar pelepah pisang dengan ketebalan $2,5 \mathrm{~mm}$ 


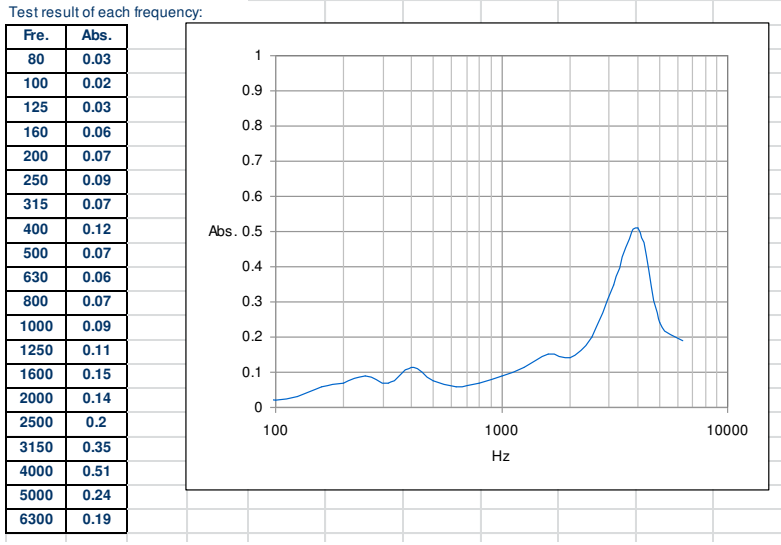

Gambar 2 : Grafik hasil pengujian sampel dari Bonggol

Pisang

- Hasil pegujian dari bahan dasar Tandan pisang dengan ketebalan $2,5 \mathrm{~mm}$

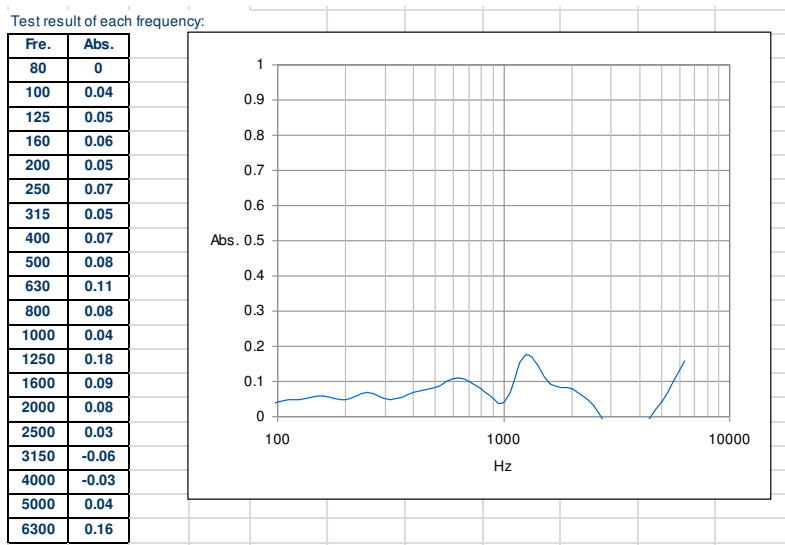

Gambar 3 : Grafik hasil pengujian sampel dari Tandan Pisang

Pengujian material tandan dan pelepah pisang diujikan dari frekuensi $60 \mathrm{~Hz}$ hingga $6500 \mathrm{~Hz}$. Kita tidak menggunakan keseluruhan frekuensi untuk mengambil sampel. Batasan yang diambil yaitu sesuai dengan indera pendengaran manusia yaitu $125 \mathrm{~Hz}-2000 \mathrm{~Hz}$ (Stamper \& Johnson, 2015). Berikut tabel perbandingan antara panel pelepah pisang dengan tandan pisang.

\begin{tabular}{|c|c|c|}
\hline & Pele pah & Tandan \\
\hline Fre. & Abs. & Abs. \\
\hline 80 & 0,03 & 0 \\
\hline 100 & 0,02 & 0,04 \\
\hline 125 & 0,03 & 0,05 \\
\hline 160 & 0,06 & 0,06 \\
\hline 200 & 0,07 & 0,05 \\
\hline 250 & 0,09 & 0,07 \\
\hline 315 & 0,07 & 0,05 \\
\hline 400 & 0,12 & 0,07 \\
\hline 500 & 0,07 & 0,08 \\
\hline 630 & 0,06 & 0,11 \\
\hline 800 & 0,07 & 0,08 \\
\hline 1000 & 0,09 & 0,04 \\
\hline 1250 & 0,11 & 0,18 \\
\hline 1600 & 0,15 & 0,09 \\
\hline 2000 & 0,14 & 0,08 \\
\hline 2500 & 0,2 & 0,03 \\
\hline 3150 & 0,35 & $-0,06$ \\
\hline 4000 & 0,51 & $-0,03$ \\
\hline 5000 & 0,24 & 0,04 \\
\hline 6300 & 0,19 & 0,16 \\
\hline & & \\
\hline
\end{tabular}

Tabel 3 : perbandingan Hasil pengujian Pelepah pisang dengan Tandan pisang

Dari hasil perbandingan tabel tersebut dapat diketahui bahwa :

- Pengujian di bawah $400 \mathrm{~Hz}$ tidak melebihi koesien absorpsi 0,10

- Untuk material pelepah pisang pada pengujian frekuensi di atas $1000 \mathrm{~Hz}$ mempunyai koefisien absorpsi lebih dari 0,10 sedangkan untuk tandan pisang mempunyai koefisien absorpsi dikisaran 0,10 .

- Untuk kedua material tersebut, pengujian frekuensi diatas $2000 \mathrm{~Hz}$ 
untuk Pelepah Pisang cenderung naik koefisien abs sedangkan untuk tandan Pisang cenderung turun.

Sebagai material daur ulang, tandan Pisang dan pelepah Pisang termasuk jenis panel Absorpsi dimana dalam pembuatan material tersebut, bahan dicetak dalam lembaran dengan ketebalan 2,5 mm. Permukaan material antara tandan pisang dengan pelepah pisang mempunyai tekstur yang berbeda. Untuk tandan pisang permukaannya lebih halus dibandingkan dengan pelepah pisang.

\section{SIMPULAN}

Dari data hasil tabel pengukuran dapat disimpulkan bahwa, material yang terbuat dari pelepah pisang dan tandan pisang termasuk dalam golongan panel abrsobsi dimana material tersebut dapat diaplikasikan pada dinding interior, bukan eksterior. Walaupun dapat diaplikasikan pada dinding interior, masih diperlukan perlakuan tertentu (penelitian lebih lanjut) agar panel tersebut tahan terhadap faktor lingkungan.

Jika dilihat dari hasil tabel pengukuran, panel pisang yang diujikan dapat dipakai sebagai penyerap suara, dimana komposisi bahan terbuat dari alam dan memiliki tekstur yang cukup lembut sehingga dapat menyerap suara yang tidak diinginkan. Pemakaian dapat disesuaikan dengan RT (Reveberation Time) yang ingin dicapai, jika diinginkan RT yang cukup rendah maka pengaplikasian material tersebut dapat ditambah. Bahan ini dapat diaplikasikan untuk interior yang diperuntukkan sebagai pertunjukan Drama, pemutaran film, bandara atau interior yang membutuhkan persyaratan khusus.

Sebagai material daur ulang dari bahan alami, untuk memproduksi material tersebut harus disesuaikan dengan keadaan daerah tempat produksi. Penggunaan tandan dan pelepah pisang merupakan bahan utama dalam pembuatan panel tersebut.

Adapun kendala yang harus dihadapi yaitu mesin pres dan pengering yang akan digunakan. Jika pada pengujian ini masih menggunakan teknik manual (pengeringan masih mengandalkan panas matahari) maka kendala yang dihadapi yaitu hasil akhir dari panel tersebut tidak rata karena perbedaan suhu panas yang diterima. Diharapkan jika menggunakan mesin pengering, secara otomatis pengeringan lebih merata.

\section{UCAPAN TERIMA KASIH}

Ucapan terima kasih ditujukan kepada Bapak Ambardi dari Bardiju Paper Art dan 
Bapak Dr. Ir. Komang Mertayasa, M.T dari Fakultas Teknik Industri, Fisika Teknik, ITB Bandung.

\section{DAFTAR PUSTAKA}

Adiwijaya, M. (2011). Peran pemerintah, industri ritel, dan masyarakat dalam membatasi penggunaan kantong plastik sebagai salah satu upaya pelestarian lingkungan. Petra Christian University.

Bazley, C., Vink, P., \& de Jong, A. (2014). Environmental comfort design considerations for future control room interiors. Paper presented at the Proc. of the 5th International Conference on Applied Human Factors and Ergonomics AHFE.

Berardi, U., \& lannace, G. (2015). Acoustic characterization of natural fibers for sound absorption applications. Building and Environment, 94, 840852.

Cai, X., Guo, Q., Hu, G., \& Yang, J. (2014). Ultrathin low-frequency sound absorbing panels based on coplanar spiral tubes or coplanar Helmholtz resonators. Applied Physics Letters, 105(12), 121901.

Dewi, A. K. (2015). MATERIAL AKUSTIK SERAT PELEPAH PISANG (MUSA ACUMINAX BALBASIANA CALLA) SEBAGAI PENGENDALI POLUSI BUNYI. Jurnal Fisika Unand, 4(1).

Dragna, D., Pineau, P., \& Blanc-Benon, P. (2016). Time-domain propagation in porous media using the auxiliary differential equation method: Application for outdoor acoustics. The Journal of the Acoustical Society of America, 139(4), 2009-2009.
Dupont, T., Verdière, K., Leclaire, P., \& Panneton, R. (2015). A method to control the lateral boundary condition effects in the characterization of acoustic materials in an impedance tube. Paper presented at the INTERNOISE and NOISE-CON Congress and Conference Proceedings.

Groat, L. N., \& Wang, D. (2013). Architectural research methods: John Wiley \& Sons.

Indrawati, E., \& Tirono, M. (2012). Koefisien Penyerapan Bunyi Bahan Akustik dari Pelepah Pisang dengan Kerapatan yang Berbeda. Jurnal Neutrino.

Jayamania, E., Hamdanb, S., Ezhumalaia, P., \& Bakria, M. K. (2016). Investigation On Dielectric And Sound Absorption Properties of Banana Fibers Reinforced Epoxy Composites. Jurnal Teknologi, 78(6-10), 97-103.

Jayanti, N. D. (2013). Analisis faktor-faktor yang mempengaruhi green purchasing (survei pada pelanggan Tupperware di Kota Malang). Jurnal Administrasi Bisnis, 5(1).

Khuriati, A., \& Komaruddin, E. (2006). Disain peredam suara berbahan dasar sabut kelapa dan pengukuran koefisien penyerapan bunyinya. Berkala Fisika, 9(1), 15-25.

Nurjannah, S. (2016). Koefisien Penyerapan Dinding Akustik dari Komposisi Bahan Pelepah Pisang, Eceng Gondok dan Rak Telur. Univeritas Islam Negeri Alauddin Makassar.

Permanasari, M. D., Larasati, D., \& Widiawati, D. (2014). Banana Bark as A Part of Acoustic Design Unit by Hybrid Technology Application. Journal of Visual Art and Design, 6(2), 143-150.

Pierre, J., Guillermic, R.-M., Elias, F., Drenckhan, W., \& Leroy, V. (2013). Acoustic characterisation of liquid foams with an impedance tube. 
SE, S. M. (2002). Membuat kertas daur ulang berwawasan lingkungan: Niaga Swadaya.

Shahani, F., Soltani, P., \& Zarrebini, M. (2014). The Analysis of Acoustic Characteristics and Sound Absorption Coefficient of Needle Punched Nonwoven Fabrics. Journal of Engineered Fabrics \& Fibers (JEFF), 9(2).

Stamper, G. C., \& Johnson, T. A. (2015). Auditory function in normal-hearing, noise-exposed human ears. Ear and hearing, 36(2), 172.

Suharyani, S., \& Mutiari, D. (2015). LIMBAH PELEPAH PISANG RAJA SUSU SEBAGAI ALTERNATIF BAHAN DINDING KEDAP SUARA. Sinektika: Jurnal Arsitektur, 13(1), 62-68.

Sutanto, A., Priatman, J., \& Mediastika, C. E. (2014). KAJIAN PENERAPAN PRINSIPPRINSIP AKUSTIK STUDI KASUS: RUANG AUDITORIUM MULTIFUNGSI GEDUNG P1 DAN P2 UNIVERSITAS KRISTEN PETRA. JURNAL DIMENSI UTAMA TEKNIK SIPIL, 1(1).

Sutanto, H. (2015). Prinsip-prinsip akustik dalam arsitektur: Kanisius.

Tholkappiyan, E., Saravanan, D., Jagasthitha, R., Angeswari, T., \& Surya, V. (2016). Prediction of acoustic performance of banana fiber-reinforced recycled paper pulp composites. Journal of Industrial textiles, 45(6), 1350-1363.

Wang, W., Arora, R., Livescu, K., \& Bilmes, J. A. (2015). Unsupervised learning of acoustic features via deep canonical correlation analysis. Paper presented at the Acoustics, Speech and Signal Processing (ICASSP), 2015 IEEE International Conference on. 